\title{
O desempenho individual de gestores intermédios da administração pública portuguesa*
}

Catarina Brandão e Filomena Jordão

\section{Introdução}

Este estudo tem por objetivo identificar a estrutura interna do desempenho individual de gestores intermédios da Administração Pública Portuguesa, procurando perceber que comportamentos de desempenho de tarefa e de desempenho contextual são valorizados por esses gestores e pelos seus supervisores, e que comportamentos os primeiros adotam.

A literatura demonstra que diferentes postos de trabalho e organizações requerem e potenciam diferentes comportamentos (e.g. Paine \& Organ, 2000), pelo que importa considerar as características de cada organização e posto de trabalho e identificar a perceção dos seus atores, nomeadamente aqueles que definem os objetivos, a estratégia, as normas e os valores da organização, na medida em que estes conhecem a fundo as especificidades do seu posto e as contingências imediatas a que este está sujeito. Isto permite identificar os comportamentos que facilitam a ação da organização e que diminuem os efeitos negativos de algumas contingências 
a que esta se encontra sujeita. Apesar de vários estudos sublinharem o impacto dos gestores no sistema organizacional, o estudo empírico da componente avaliativa dos comportamentos deste ator organizacional permanece pouco desenvolvido, particularmente no contexto da Administração Pública (AP).

No sentido de contribuirmos para colmatar essa lacuna, recorremos a modelos de desempenho individual (DI) que adotam a perspetiva avaliativa, nomeadamente o modelo proposto por Borman e Motowidlo (1993, 1999), segundo o qual o DI integra comportamentos de natureza distinta que têm impacto na concretização dos objetivos da organização e do posto de trabalho. Este modelo é associado a modelos específicos ao posto de gestor e que têm procurado identificar as diferentes categorias comportamentais presentes na sua atividade.

De forma a concretizar o objetivo do nosso trabalho, operacionalizou-se um estudo de caso simples embutido exploratório (Yin, 2008), realizando-se entrevistas semiestruturadas a gestores intermédios da AP e aos seus supervisores, e recolhendo diários de bordo dos primeiros.

O artigo começa com a exposição dos conceitos-chave, subjacentes ao trabalho desenvolvido, e as teorias que o suportam, focando o conceito de desempenho individual e as suas especificidades no posto de gestor. Termina-se o enquadramento teórico com ideias relativas ao contexto organizacional que focamos, a Administração Pública. De seguida, na secção do método, apresenta-se o caso estudado, assim como as formas através das quais se recolheu informação para concretizar o objetivo deste estudo e dar resposta às duas questões de investigação definidas.
Posteriormente, os resultados obtidos são apresentados e discutidos, terminando o artigo com uma reflexão acerca das implicações desses resultados e pistas futuras de investigação.

\section{Enquadramento teórico}

O desempenho individual (DI) representa o conjunto dos comportamentos observáveis que os trabalhadores adotam e que são relevantes para a organização ${ }^{1}$, influenciando a concretização dos seus objetivos (Campbell, Ford, Rumsey, Pulakos, Borman, Felker, Vera, \& Riegelhaupt, 1990; Campbell, Mchenry, \& Wise, 1990).

Apesar de podermos encontrar em alguns trabalhos clássicos (e.g. SELzNICK, 1948; SMITH, 1976; TAYLOR, 1916) alguma sensibilidade para a variabilidade de comportamentos dos trabalhadores que constituem o DI e influenciam o desempenho ou eficácia, só nos últimos 40 anos se registra uma postura de análise mais sistemática da natureza diferenciada desses comportamentos (e.g. KATZ \& KaHN, 1978), considerando, a par dos comportamentos diretamente relacionados com o sistema técnico da organização ${ }^{2}$, aqueles que não estando diretamente dirigidos ao sistema técnico, influenciam o contexto onde este se desenrola.

Uma dessas sistematizações, e que adotamos no nosso trabalho, postula que o DI em qualquer posto de trabalho integra duas dimensões: desempenho de tarefa e desempenho contextual (BORMAn \& Motowidlo, 1993, 1997). A primeira compreende os comportamentos que contribuem direta e indiretamente para o sistema técnico da organização, seja com a implementação de partes desse sistema, como a transformação de inputs (apoio 
direto), seja com o apoio a essas transformações, através do fornecimento de inputs ou serviços e posterior distribuição de outputs (apoio indireto). O nível de desempenho de tarefa do indivíduo traduz, assim, a eficácia com que este desempenha as atividades que contribuem para o sistema técnico da organização. A dimensão do desempenho contextual, por sua vez, integra os comportamentos que não estando diretamente relacionados com a função específica do trabalhador, moldam o contexto organizacional, social e psicológico que serve como catalisador crítico para o desenvolvimento das atividades e processos da tarefa (BORMAN \& MotowidLo, 1993, 1997).

Este tipo de desempenho não visa suportar tanto o sistema técnico (como o anterior), mas antes a organização de uma forma mais ampla, o ambiente social e psicológico onde o sistema técnico deve funcionar. Esta dimensão do DI condiciona a cultura e o clima da organização (HATTRUP, O'Connell, \& Wingate, 1998), influenciando o seu desempenho ou eficácia (BORMAN \& MOTOWIDlo, 1993; BORMAN, Penner, Allen, \& Motowidlo, 2001).

Os autores Borman e Motowidlo (1997) distinguem o desempenho de tarefa e contextual a nível conceptual e empírico, com base em aspetos fundamentais. Em primeiro lugar, sublinham que as atividades de tarefa tendem a variar entre postos de trabalho, enquanto as atividades e processos de desempenho contextual são geralmente idênticos; em segundo lugar, as atividades e os processos de desempenho de tarefa podem ser mais facilmente prescritos pelo papel do que as atividades e os processos do desempenho contextual; e, finalmente, as atividades e os processos de desempenho de tarefa estarão relacionados com competências cognitivas e o desempenho contextual, com características individuais de personalidade. Para se distinguir o domínio do desempenho de tarefa e o contextual importa considerar as tarefas para as quais o trabalhador foi contratado (e que requerem comportamentos de tarefa), o âmbito do seu posto de trabalho ${ }^{3}$ e o facto dos comportamentos contextuais o ultrapassarem, por implicarem esforço extra e iniciativa do trabalhador.

Vários estudos têm corroborado esta distinção (e.g. BORMAN \& MOTOWIDLO, 1993,

$\quad$ “O nível de
desempenbo de
tarefa do
indivíduo traduz,
assim, a eficácia
com que este
desempenba as
atividades que
contribuem para
o sistema técnico
da organização."

1997; Borman et al., 2001; Coleman \& Borman, 2000), salientando-se a sua pertinência, nomeadamente a nível de práticas de recrutamento e seleção (RS) (Hattrup et al., 1998), podendo apoiar a organização a identificar a natureza dos comportamentos mais relevantes num determinado posto de trabalho, a partir da selecão dos indivíduos que demonstrem 
possuir as competências ou características que potenciam a sua adoção. A estrutura interna do desempenho de tarefa é específica a cada posto de trabalho em particular, enquanto a do desempenho contextual é transversal à maioria dos postos de trabalho (BORMAN \& MOTOWIDLO, 1993).

Baseando-se na investigação acerca dos comportamentos contextuais, de cidadania organizacional e pró-sociais, Borman e colegas (2001) identificam as três subdimensões que compõem o desempenho contextual, cada uma delas com comportamentos específicos. A primeira, Suporte Pessoal, engloba os comportamentos dirigidos aos membros da organização, tais como "ajudar" (e.g. dar suporte emocional a colegas), "cooperar" (e.g. aceitar sugestões, privilegiar os objetivos de equipa), "cortesia" (e.g. ter consideração e tato nas relações) e "motivar" (e.g. incentivar os colegas). A segunda, Suporte Organizacional, engloba comportamentos dirigidos à organização, como "representar" (e.g. defender a organização), "lealdade" (e.g. permanecer na organização apesar de dificuldades temporárias) e "concordar" (e.g. concordar com regras e procedimentos). A terceira e última subdimensão, Iniciativa Conscienciosa, engloba comportamentos dirigidos para o posto de trabalho/a tarefa, tais como "persistir" (e.g. revelar esforço extra), "ter iniciativa" (e.g. fazer o que for necessário para concretizar objetivos) e "desenvolver-se" (e.g. realizar formações, utilizando o seu próprio tempo e recursos).

Apesar da transversalidade desta dimensão do DI, Borman e Motowidlo (1993) e Conway $(1999,2000)$ sublinham a necessidade de estudar esta dimensão nos postos de trabalho cujas atividades se revestem de especificidade, como é o caso do gestor, de forma a percebermos qual a sua estrutura nestes postos em particular.

\section{O desempenho individual do gestor}

Os gestores são os atores organizacionais que possuem a responsabilidade sobre uma determinada organização ou algumas das suas unidades. São considerados os principais responsáveis por garantir que o sistema funcione (DAFT \& SteEres, 1986), refletindo-se as suas escolhas em toda a atividade organizativa (Duncan \& Weiss, 1979; Hosking \& Morley, 1991). Os seus comportamentos não apoiam diretamente o sistema técnico central da organização, na medida em que não lhes cabe o desenvolvimento das principais atividades de transformação da organização, desenvolvendo antes comportamentos que garantam que essas atividades de transformação ocorram (Borman \& MOTOWIDlo, 1993).

Cabe ao gestor prestar serviços ao sistema técnico e atuar sobre outros trabalhadores (supervisionando-os, por exemplo), de modo a que estes possam desenvolver as atividades de transformação principal da organização. Conforme demonstrado por Mintzberg (1994), a atividade desenvolvida pelo gestor caracteriza-se por ser breve, variada e descontínua. Sendo permanentemente confrontado com solicitações (externas e internas), ele socorre-se das informações a que tem acesso pelo seu estatuto e que vai recolhendo de forma continuada (frequentemente sob um registo informal) e privilegiadamente por via oral. Baseado nessas informações, que na maior parte das vezes não explicita formalmente, ele vai planificando e tomando decisões, sendo fortemente condicionado pelos acontecimentos.

Este posto de trabalho também se caracteriza pelo desenvolvimento de 
atividades rotineiras (frequentemente em detrimento da realização de atividades de planeamento), com o gestor a envolver-se também em rituais organizacionais onde desempenha o papel de símbolo organizacional, recebendo convidados e clientes, presidindo a jantares, etc.

Apesar dos vários estudos que têm abordado a atividade dos gestores, procurando sistematizar os seus comportamentos (e.g. Mintzierg, 1973; YukL, 1989), são poucos os que abordam empiricamente o comportamento deste ator organizacional sob o prisma do desempenho/eficácia, ou seja, focando a componente avaliativa dos seus comportamentos. O estudo do comportamento do gestor, sob este prisma, foca-se nos requisitos críticos do seu trabalho (BORMAN \& Brush, 1993), ou seja, nos comportamentos que permitem diferenciar o trabalho eficaz e ineficaz, uma abordagem que importa privilegiar (MinTZBERG, 1973).

Borman e Brush (1993) adotam esta perspetiva quando avançam com um modelo integrado dos comportamentos que compõem o DI do gestor, sistematizando-os em 4 subdimensões, (1) comportamentos de interação e comunicação (comunicar e manter os outros informados, representar a organização junto do exterior, manter boas relações de trabalho, e influenciar), (2) comportamentos de liderança e supervisão (orientar, avaliar e motivar subordinados, treinar, formar e desenvolver subordinados, e coordenar subordinados e recursos), (3) comportamentos técnicos e de gestão (planear e organizar, proficiência, administração e tarefas burocráticas, decidir/resolver problemas, provimento de pessoal, monitorar e controlar recursos, delegar, recolher, e interpretar dados) e, por último, (4) comportamentos e capacidades pessoais (persistir em alcançar objetivos, lidar com crises e estresse, compromisso organizacional).

Conway (1996) considera que as primeiras três subdimensões representam o desempenho de tarefa do gestor e que a última remete para o seu desempenho contextual, dimensão do DI que requer ainda clarificação. No posto de gestor, algumas categorias de comportamento de desempenho de tarefa dependem, em grande medida, de comportamentos de desempenho contextual, dificultando a distinção entre a dimensão de desempenho de tarefa e contextual neste posto. Tomemos o comportamento "planear e organizar", que Borman e Brush (1993) integram no DI do gestor e cujo sucesso requer que se crie um ambiente de trabalho que é promovido com a adoção de comportamentos contextuais, como os de Suporte Pessoal (Coleman \& Borman, 2000; Conway, 1996). Outros comportamentos de desempenho de tarefa, como "administração e tarefas burocráticas", não serão tão influenciados pela adoção de comportamentos contextuais.

Ao procurar identificar a estrutura interna do DI do gestor, é, assim, fundamental considerar as especificidades deste posto, nomeadamente o facto de este requerer ação sobre outros trabalhadores e exigir comportamentos de representação formal da organização. Estas especificidades fazem com que alguns comportamentos, que são de natureza contextual em postos de não gestão, representem comportamentos de tarefa em postos de gestão. Importa ainda notar que o gestor concretiza largamente os objetivos do seu posto de trabalho através da ação de outros, o que requer da sua parte comportamentos de liderança em relação aos subordinados, de modo a garantir que estes saibam o que fazer e possuam as 
capacidades e a motivação necessárias para agir (CONWAY, 1999).

Isto significa que os comportamentos de liderança do gestor, porque visam explicitamente alcançar objetivos (criando condições para a sua concretização), são específicos ao posto de gestão e possuem uma ação indireta sobre o sistema técnico. Os subordinados do gestor, pares, supervisores e elementos exteriores à organização são diferentes "alvos" do seu comportamento, que importa considerar quando procuramos compreender a natureza dos seus comportamentos. Um comportamento de motivação ou a apresentação de uma sugestão a um subordinado remetem para o desempenho de tarefa do gestor, na medida em que visam dotar o subordinado de competências para concretizar um objetivo. Mas quando o mesmo comportamento é adotado em relação a um colega do gestor, ele assume a natureza de desempenho contextual, dado que não traduz um comportamento específico do gestor dirigido à concretização explícita de um objetivo. Representa antes um comportamento que promove o contexto organizacional, social e psicológico que serve de catalisador do sistema técnico nuclear, facilitando a concretização desse objetivo.

As especificidades do posto do gestor e a pertinência da sistematização desempenho de tarefa/desempenho contextual sublinham a necessidade de se procurar compreender a estrutura interna destas dimensões do DI neste posto de trabalho.

\section{A Administração Pública enquanto contexto}

A investigação acerca do DI tem realçado a importância das características da organização e do posto de trabalho na compreensão deste e do nível de eficácia exibido, o que sublinha a pertinência de se compreender o DI em contextos específicos, como o da Administração Pública (AP). As organizações deste contexto caracterizam-se por culturas hierárquicas e não participativas (Muldrow, Buckley, \& SCHAY, 2002), exibindo um elevado nível de estruturação e orientação para as regras e um processo de tomada de decisão tendencialmente autocrático (SCHRAEDER, TEARs, \& Jordan, 2005).

Traduzem uma "cultura antecipatória" (VALLE, 1999), sendo os trabalhadores formados para antecipar problemas, respeitar os requisitos de procedimentos e de papéis e, dessa forma, garantir a estabilidade do sistema. A organização garante o cumprimento do desempenho de tarefa com a prescrição de comportamentos, reforçada com a formalização em descrições escritas do conteúdo dos postos de trabalho (instrumento especialmente presente nas organizações burocráticas) (Morrison, 1996). Estes sistemas, cuja atividade é bastante regulada por regras e procedimentos formais, inibem a adoção de comportamentos contextuais (PAInE \& Organ, 2000). Enfatizam o que deve e o que não deve ser feito pelos trabalhadores, inibindo comportamentos espontâneos, a iniciativa dos trabalhadores que permite responder a situações diferentes e urgentes, e que não se encontram previstas nas regras cujo seguimento se enfatiza.

Ao reforçar que as ações e os procedimentos regulados permitem a obtenção de recompensas, as organizações levam a que os trabalhadores se foquem nesses aspetos, enquanto as estruturas mais orgânicas promovem a adoção de comportamentos espontâneos (Morrison, 1996). No mesmo sentido, o comportamento contextual «concordar», que se refere a adotar regras e respeitar a autoridade, é valorizado em 
contextos burocráticos (BORMAN \& Motowidlo, 1993), dado que reforça as características da organização. O facto de as organizações da AP se inserirem hoje em meios cada vez mais dinâmicos e complexos (Fairholm, 2004; Schraeder et al., 2005) tem-nas pressionado a adotar novas formas organizacionais, mais achatadas, e a tornarem-se menos burocráticas e mais empreendedoras (Arvonen \& EkVAll, 1999; KANTER, 1989).

As discussões acerca do que mudar na AP e como mudar (SPICER, 2008; VAN WART, 2003) parecem partilhar o objetivo de a AP se tornar mais flexível e adaptativa (NutT, 1995), economicamente mais eficiente e atenta às necessidades dos seus clientes/utentes (Posner \& Schmidt, 1982). Procura-se que as culturas hierárquicas e não participativas sejam abandonadas, partilhando a liderança e encorajando a criatividade e a inovação (MULDRow et al., 2002), e enfatiza-se a «orientação para a melhoria do desempenho» (Kelman, 2007, p. 239), menor burocratização, a gestão por objetivos e a avaliação da eficácia/desempenho (VAN WART, 2003). Exige-se um desempenho mais elevado aos seus membros e esforços extra, de modo a sobressaírem e manterem os seus postos de trabalho. O desempenho contextual revela-se particularmente importante neste ambiente complexo e dinâmico, na medida em que estes comportamentos «lubrificam a máquina social da organização» e «providenciam a flexibilidade necessária para trabalhar sob muitas condições inesperadas» (Smith, Organ, \& NeAr, 1983, p. 654).

Este estudo de caso pretende contribuir para a clarificação da estrutura interna do DI dos gestores intermédios da Administração Pública e para a discussão do papel do gestor na mudança da AP, partindo da integração teórica das sistematizações de desempenho de tarefa do gestor e desempenho contextual, de uma forma contextualizada.

\section{Método}

A ausência de estudos acerca do DI de gestores portugueses, segundo o prisma do DI, orientou-nos para a opção por um design qualitativo de estudo de caso simples

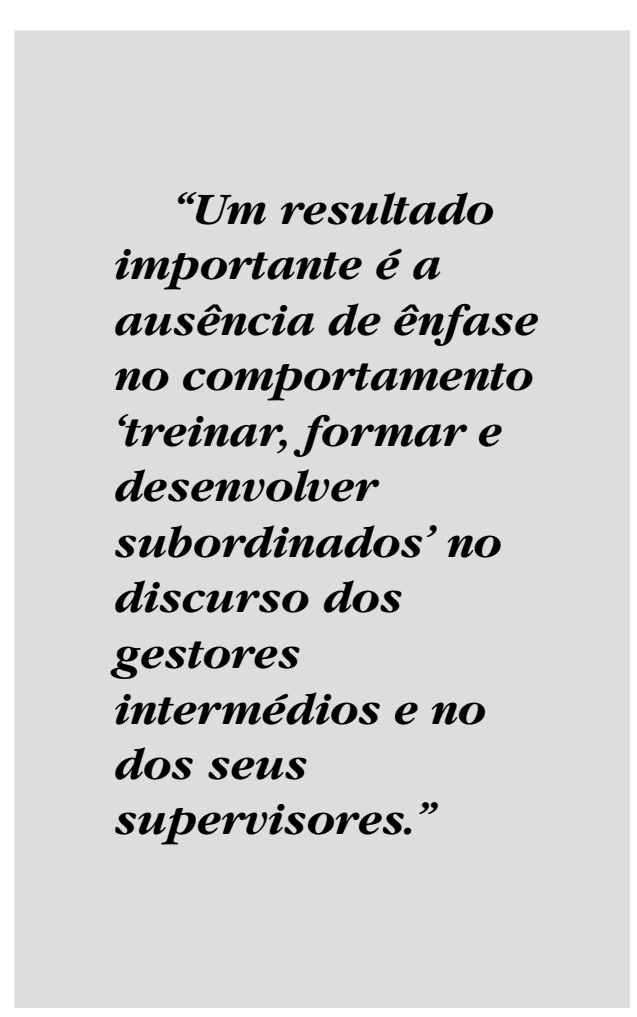

embutido exploratório (YIN, 2008), definindo como objetivo identificar a estrutura interna do Desempenho Individual dos gestores intermédios da AP. Para concretizar este objetivo foram definidas as seguintes questões de investigação (1) Quais os comportamentos de desempenho de tarefa e desempenho contextual valorizados pelos gestores intermédios da AP e seus 
supervisores? e (2) Quais os comportamentos de desempenho de tarefa e desempenho contextual adotados pelos gestores intermédios da AP?

\section{Caso e participantes}

A diversidade que caracteriza a administração pública portuguesa (APP) (e.g. número e tamanho das estruturas, áreas de atividade e formação dos seus trabalhadores) colocou desde logo a dúvida acerca da organização de onde selecionaríamos o posto dirigente a estudar. Optou-se por eleger como contexto de estudo um instituto público no sector da Educação (cujas unidades orgânicas são as faculdades). Os órgãos de gestão das faculdades são, atualmente, constituídos na sua maioria por docentes da organização que, a par das atividades de gestão, continuam a desenvolver as atividades inerentes à função de docente. Considerando que a seleção do posto de dirigente máximo da organização implicaria esta dualidade de papéis, que pareceu importante evitar, selecionou-se como caso para análise o posto dos gestores profissionais que ocupam a posição hierárquica mais elevada nas faculdades - os diretores de serviços (DS). Este posto de trabalho, de Dirigente Intermédio de $1^{\circ}$ grau $^{4}$, encontra-se sujeito ao Estatuto do Pessoal Dirigente da APP e ao Regulamento Orgânico de cada faculdade, estando os seus titulares sujeitos a responsabilização civil, criminal, disciplinar e financeira. $\mathrm{Na}$ maior parte das unidades orgânicas deste contexto, os DS são nomeados por despacho do Reitor da Universidade, sob proposta do presidente ou diretor da faculdade.

De forma a elaborar um quadro de conhecimento rico acerca do DI do posto em estudo, recolheu-se informação junto de 12 gestores intermédios (DS), cinco do sexo masculino e sete do feminino; sendo que apenas dois não possuem licenciatura. Dez destes gestores encontram-se na organização há mais de cinco anos e sete ocupam o atual posto de trabalho há menos de cinco anos. Recolheu-se igualmente informação junto de sete supervisores (presidentes/diretores das faculdades - P/D), integrados no mesmo supersistema (i.e. na mesma Universidade), dada a influência dos supervisores na definição do papel e comportamentos dos subordinados (KATZ \& KaHn, 1978). A nível dos supervisores, quatro são do sexo masculino e três do feminino; todos possuem doutoramento e a maioria (4) encontra-se na organização há mais de quatro anos.

\section{Instrumentos de recolha de informação e procedimento}

Realizaram-se entrevistas semiestruturadas aos DS e aos seus supervisores (P/D), procurando dirigir o seu discurso para a componente avaliativa do desempenho do DS. O guião aplicado aos DS (consultar Apêndice A) era composto por cinco questões, organizadas em duas secções, a primeira focava os comportamentos valorizados no posto de DS $^{5}$ e a segunda focava os comportamentos efetivamente adotados pelos $\mathrm{DS}^{6} \mathrm{O}$ guião aplicado aos supervisores focava os comportamentos valorizados no posto de DS, sendo equivalente à primeira parte do guião dos DS. No total foram realizadas 18 entrevistas (11 a DS e 7 a P/D), no local de trabalho dos participantes, gravadas com a sua autorização e, mais tarde, transcritas. Foram ainda aplicados diários de bordo aos DS, onde se solicitava que registassem os comportamentos adotados por si durante o seu dia de trabalho. Foram devolvidos sete diários de bordo preenchidos, num total de 
12 solicitados. A informação recolhida foi submetida à análise de conteúdo (BARDIN, 1977), recorrendo ao Nud*ist ${ }^{7}$.

No que se refere ao procedimento de repartição dos dados, definimos à partida um conjunto de categorias (rubricas de classificação) mutuamente exclusivas a nível do seu significado, de acordo com a estrutura do DI adotada neste trabalho. O sistema de categorias traduzia, assim, as sistematizações de DI avançadas por Borman e Motowidlo (1993), Borman e Brush (1993), Conway (1999) e Borman e colegas (2001), à luz das especificidades do gestor. A unidade de análise foi o parágrafo, tendo sido codificadas 2.379 unidades de registo no total. O método de contagem adotado foi a presença de cada categoria no discurso dos entrevistados e nos diários de bordo, independentemente da frequência dessa presença.

\section{Resultados}

\section{Comportamentos valorizados pelos gestores intermédios e seus supervisores}

Identificou-se no discurso dos DS referência a todos os comportamentos das três subdimensões de desempenho de tarefa do gestor presentes no modelo de Borman e Brush (1993) e a todas as subdimensões de desempenho contextual (Quadro 1). No discurso de todos os $\mathrm{P} / \mathrm{D}$, foram valorizados comportamentos de desempenho de tarefa dos DS e apenas um não se referiu ao desempenho contextual. Os diferentes comportamentos de desempenho de tarefa são identificados no discurso dos P/D de forma semelhante e as subdimensões de desempenho contextual identificadas como presentes no discurso de mais $\mathrm{P} / \mathrm{D}$ são Suporte Organizacional, sobretudo o comportamento "concordar", e Suporte Pessoal, com os comportamentos "cortesia e apoiar" e "cooperar". Não foram identificados no discurso de nenhum dos participantes os comportamentos contextuais "ajudar", "motivar" e "representar".

\section{Comportamentos de desempe- nho de tarefa e contextual adotados pelos gestores intermédios}

Identificam-se comportamentos de desempenho de tarefa no discurso de todos os DS, com exceção de um DS, que optou por não descrever o seu dia de trabalho, não identificando comportamentos de desempenho de tarefa, nem contextual (Quadro 2). A dimensão de desempenho contextual foi identificada no discurso de apenas sete DS. Apesar de identificarmos referência às duas dimensões do DI, quando se adota como método de contagem a frequência da presença das categorias de análise no seu discurso a nível da adoção de comportamentos, verifica-se que se referem muito mais frequentemente aos comportamentos de desempenho de tarefa do que aos de desempenho contextual. Todos os comportamentos de desempenho de tarefa são identificados no discurso dos DS quando estes se referem aos comportamentos adotados por si, com exceção do comportamento "influenciar". A nível de desempenho contextual, não há referência à adoção dos comportamentos "ajudar", "cooperar", "motivar", "lealdade" e "iniciativa".

Uma leitura integrada destes resultados permite perceber a valorização de comportamentos das duas dimensões do DI (tarefa e contextual) no discurso de todos os DS, observando-se no geral uma coerência entre os comportamentos de desempenho de tarefa identificados como os mais valorizados e mais adotados. 
Quadro 1: comportamentos valorizados pelos gestores intermédios (DS) e supervisores $(\mathrm{P} / \mathrm{D})$

\begin{tabular}{|c|c|c|c|c|}
\hline & \multicolumn{2}{|c|}{ Gestores intermédios $(\mathrm{N}=12)$} & \multicolumn{2}{|c|}{ Supervisores $(\mathrm{N}=7)$} \\
\hline & Presença/ausência & Referências & Presença/ausência & Referências \\
\hline A. Desempenho de tarefa & 11 & 295 & 7 & 159 \\
\hline 1.Interação e Comunicação & 8 & & 5 & \\
\hline $\begin{array}{l}\text { Comunicar e manter os } \\
\text { outros informados }\end{array}$ & 5 & & 3 & \\
\hline Representar a organização & 4 & & 2 & \\
\hline Influenciar & 3 & & 0 & \\
\hline 2. Liderança e Supervisão & 10 & & 6 & \\
\hline Orientar, avaliar e motivar & 8 & & 4 & \\
\hline $\begin{array}{l}\text { Treinar, formar e } \\
\text { desenvolver subordinados }\end{array}$ & 3 & & 0 & \\
\hline $\begin{array}{l}\text { Coordenar subordinados e } \\
\text { recursos }\end{array}$ & 10 & & 5 & \\
\hline 3. Técnicos e de Gestão & 11 & & 7 & \\
\hline Planear e organizar & 6 & & 4 & \\
\hline Proficiência profissional & 7 & & 6 & \\
\hline $\begin{array}{l}\text { Administração e tarefas } \\
\text { burocráticas }\end{array}$ & 4 & & 0 & \\
\hline $\begin{array}{l}\text { Decidir/resolver } \\
\text { problemas }\end{array}$ & 7 & & 5 & \\
\hline Provimento de pessoal & 4 & & 0 & \\
\hline $\begin{array}{l}\text { Monitorar e controlar } \\
\text { recursos }\end{array}$ & 9 & & 6 & \\
\hline Delegar & 4 & & 1 & \\
\hline $\begin{array}{l}\text { Recolher e interpretar } \\
\text { dados }\end{array}$ & 4 & & 1 & \\
\hline B. Desempenho contextual & 11 & 81 & 6 & 58 \\
\hline 4. Suporte Pessoal & 8 & & 5 & \\
\hline Ajudar & 0 & & 0 & \\
\hline Cooperar & 4 & & 3 & \\
\hline Cortesia e apoiar & 8 & & 4 & \\
\hline Motivar & 0 & & 0 & \\
\hline 5. Suporte organizacional & 6 & & 6 & \\
\hline Representar & 0 & & 0 & \\
\hline Lealdade & 1 & & 1 & \\
\hline Concordar & 6 & & 6 & \\
\hline 6. Iniciativa conscienciosa & 7 & & 3 & \\
\hline Persistir & 4 & & 2 & \\
\hline Iniciativa & 4 & & 2 & \\
\hline Autodesenvolver-se & 3 & & 0 & \\
\hline
\end{tabular}

Fonte dos dados: entrevistas realizadas (aos DS e aos P/D) e os diários de bordo recolhidos (dos DS)

Nota: "Referências" remete para o número de vezes que as categorias estavam presentes no discurso dos participantes. 


\section{Quadro 2: comportamentos adotados pelos gestores intermédios (DS)}

\begin{tabular}{|c|c|c|}
\hline & \multicolumn{2}{|c|}{ Gestores intermédios $(\mathrm{N}=12)$} \\
\hline & Presença/ausência & Referências \\
\hline A. Desempenho de tarefa & 10 & 375 \\
\hline 1. Interação e Comunicação & 10 & \\
\hline Comunicar e manter os outros informados & 8 & \\
\hline Representar a organização & 8 & \\
\hline Influenciar & 0 & \\
\hline 2. Liderança e Supervisão & 9 & \\
\hline Orientar, avaliar e motivar & 7 & \\
\hline Treinar, formar e desenvolver subordinados & 4 & \\
\hline Coordenar subordinados e recursos & 8 & \\
\hline 3. Técnicos e de Gestão & 10 & \\
\hline Planear e organizar & 6 & \\
\hline Proficiência profissional & 9 & \\
\hline Administração e tarefas burocráticas & 10 & \\
\hline Decidir/resolver problemas & 8 & \\
\hline Provimento de pessoal & 2 & \\
\hline Monitorar e controlar recursos & 7 & \\
\hline Delegar & 1 & \\
\hline Recolher e interpretar dados & 8 & \\
\hline B. Desempenho contextual & 7 & 50 \\
\hline 4. Suporte Pessoal & 1 & \\
\hline Ajudar & 0 & \\
\hline Cooperar & 0 & \\
\hline Cortesia e apoiar & 1 & \\
\hline Motivar & 0 & \\
\hline 5. Suporte organizacional & 3 & \\
\hline Representar & 3 & \\
\hline Lealdade & 0 & \\
\hline Concordar & 1 & \\
\hline 6. Iniciativa conscienciosa & 7 & \\
\hline Persistir & 5 & \\
\hline Iniciativa & 0 & \\
\hline Autodesenvolver-se & 4 & \\
\hline
\end{tabular}

Fonte dos dados: entrevistas realizadas e diários de bordo recolhidos (ambos aos DS)

Nota: "Referências" remete para o número de vezes que as categorias estavam presentes no discurso dos participantes.

Os participantes enfatizam no seu discurso muito mais frequentemente os comportamentos de desempenho de tarefa do que de desempenho contextual, tanto a nível de valorização como de adoção de comportamentos. Especificamente a nível do desempenho de tarefa, observa-se alguma correspondência entre os comportamentos que a nível de valorização e adoção são mais enfatizados no discurso dos participantes.

Contudo, o comportamento que mais DS referem adotar, "administração e tarefas burocráticas", não se encontra entre os mais valorizados, fazendo parte dos menos referidos. Apesar das subdimensões de desempenho contextual surgirem de forma semelhante no discurso dos DS a nível de 
valorização, eles parecem enfatizar a adoção de comportamentos de Iniciativa Conscienciosa. Estes discursos acerca da atividade dos gestores estudados permitem-nos avançar na clarificação da estrutura interna do seu DI, concretizando o objetivo subjacente ao nosso trabalho.

Percebemos que esse DI possui a dimensão de desempenho de tarefa e de desempenho contextual, sendo o desempenho de tarefa organizado nas subdimensões (1) Interação e Comunicação, (2) Liderança e Supervisão e (3) Técnicos e de Gestão; e o desempenho contextual organizado em três subdimensões que se distinguem em função da direção dos seus comportamentos (4) Suporte Pessoal, (5) Suporte Organizacional e (6) Iniciativa Conscienciosa. Os comportamentos "ajudar" e "motivar", que sendo dirigidos a pares do gestor, traduzem o gestor a ajudar e a motivar os seus pares, não foram identificados no discurso dos participantes, o que sugere que estes comportamentos não integram o desempenho contextual dos atores organizacionais estudados (consultar Apêndice B).

\section{Discussão}

$\mathrm{Na}$ discussão dos resultados obtidos começamos por considerar a dimensão de desempenho de tarefa e de desempenho contextual, analisando a sua presença no discurso dos participantes e o significado dessa presença. De seguida, aprofunda-se a análise, focando os resultados relativos às diferentes categorias comportamentais que integram essas dimensões do Desempenho Individual (DI), e procurando interpretar esses resultados, de forma integrada, à luz da literatura, considerando que os diferentes comportamentos presentes no discurso dos participantes integram um mesmo constructo, que é o DI dos gestores intermédios da Administração Pública Portuguesa. Concluímos esta secção procurando atribuir significado aos resultados da análise do discurso dos supervisores do posto de trabalho em estudo.

Os resultados reforçam a especificidade do desempenho contextual do gestor e não apenas do seu desempenho de tarefa (BORMAN \& MOTOWIDlo, 1993; CONWAY, 1999), devendo considerar-se a direção dos comportamentos adotados quando se procede à clarificação da estrutura interna do DI deste posto. Determinados comportamentos dirigidos aos subordinados (visando diretamente alcançar objetivos de trabalho) representam comportamentos de tarefa do gestor (nomeadamente a promoção da cooperação entre subordinados, o ensino de competências e a apresentação de sugestões de trabalho), mas quando dirigidos a pares e supervisores serão comportamentos contextuais (e.g. cooperar).

Os participantes reconhecem a natureza multidimensional do DI do gestor intermédio da AP, o que revela que, para além dos comportamentos prescritos a nível de sistema técnico da organização, reconhecem os comportamentos que contribuem para a construção de um ambiente organizacional, psicológico e social positivo, que potencia a eficácia do seu sistema técnico. Contudo, os dados sugerem uma concepção mais diferenciada do desempenho de tarefa do que do desempenho contextual. Isso, associado ao facto dos comportamentos de tarefa parecerem ser mais valorizados do que os comportamentos de desempenho contextual, o que vai ao encontro da literatura (e.g. Conway, 1999), pode significar que os participantes tendem a privilegiar o primeiro em detrimento do segundo, apesar de reconhecerem a importância das duas dimensões. 
É possível que isso se deva, em certa medida, ao facto dos comportamentos de tarefa serem prescritos, o que leva a que sejam identificados imediatamente como requeridos, sendo o trabalhador avaliado pela sua concretização e pelos resultados que daí derivam (Morrison, 1996). Apesar de os comportamentos contextuais potenciarem a eficácia dos comportamentos de tarefa, os trabalhadores percebem que não serão avaliados diretamente pela sua adoção e poderão, por isso, ter maior dificuldade em estabelecer uma relação entre esses comportamentos e a eficácia da organização. Por outro lado, podem considerar que a adoção de comportamentos contextuais é privada e só a eles diz respeito (Conway, 1999), daí a menor ênfase a esses comportamentos no seu discurso.

O desenvolvimento de práticas de gestão de recursos humanos $(\mathrm{RH})$ pelos gestores de linha (como os gestores em estudo) é uma prática de trabalho de elevado desempenho, pelo que deve ser promovida (Testa \& Ehrhart, 2005). Nesse sentido, é necessário que o discurso destes gestores enfatize mais a adoção de comportamentos de formação e desenvolvimento de subordinados, de delegação, de planejamento e organização, e de provimento de pessoal, comportamentos que o discurso dos nossos participantes indicia serem pouco adotados. $\mathrm{Na}$ sua atividade de resolução de problemas e tomada de decisões o gestor recorre fundamentalmente à rede de informações que vai acumulando ao longo do tempo, acerca de diferentes indivíduos e assuntos. Ele vê-se frequentemente impedido de delegar tarefas, uma delegação que implicaria comunicar informação que ele possui de forma implícita e que não se encontra registada formalmente, exigindo o dispêndio de tempo que ele não possui, em função do ritmo acelerado do seu dia de trabalho; consequentemente, a sua atividade torna-se ainda mais variada e descontínua.

O dia-a-dia da organização é caracterizado por atividades diversas, desenvolvidas por diversas pessoas que o gestor deve coordenar, surgindo situações, frequentemente inesperadas, que são colocadas à sua consideração, como se percebe no discurso

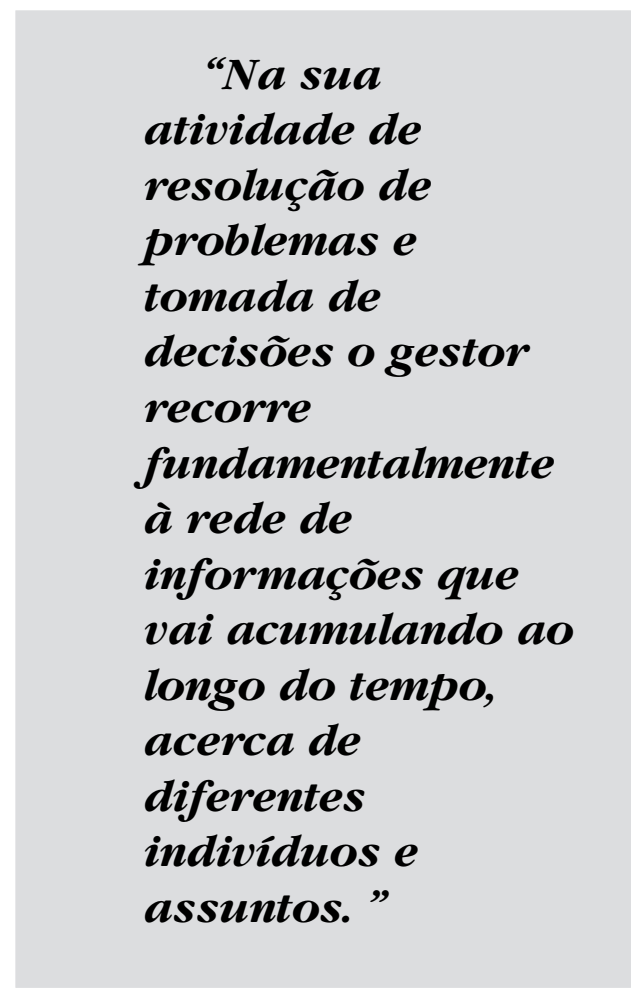

de um participante «Imprevistos (...) vêm pessoas de fora e depois há problemas que põem e que muitas vezes não são resolvidos e vêm todos ter comigo», cabendo-lhe "decidir e resolver problemas". Na presença de uma situação para a qual o gestor deve encontrar uma solução, essa torna-se a sua prioridade (MintzBerg, 1973), em detrimento de 
outros comportamentos que tenha de adotar, tendo de decidir adequada e atempadamente, ancorado nas informações a que tem acesso.

A aposta na transmissão de informação no interior da organização, capacitando outros para a resolução de problemas, criaria, contudo, condições para o gestor delegar (MintzBerg, 1994), o que lhe permitiria libertar-se, nomeadamente, de comportamentos de "administração e tarefas burocráticas" (e.g. análise de correio, resposta a pedidos de rotina, documentar acontecimentos), cuja natureza rotineira é percebida no discurso dos participantes, «muitas vezes fazemos um trabalho que... olhe, só vejo é papéis e só me chegam é papéis». A adoção deste comportamento encontra-se presente no discurso de quase todos os DS, o que parece reforçar o peso dos comportamentos rotineiros na atividade do gestor (MinTZBERG, 1973).

O facto de poucos valorizarem este comportamento poderá prender-se, exatamente, com a sua natureza burocrática e rotineira e que reflete as características associadas à AP, no que se refere ao elevado nível de formalização, apoio em regras, procedimentos e conteúdos funcionais exaustivos. Os constrangimentos burocráticos, associados aos atuais constrangimentos económicos, levam à valorização de comportamentos de verificação e controle dos recursos económicos, de modo a garantir o cumprimento de regras e a viabilidade económica da organização, o que se pode perceber na presença do comportamento "monitorar e controlar recursos" no discurso dos participantes, «os dinheiros (...) se efetivamente são suficientes ou se nós os tornamos suficientes para fazerem face às despesas».

Um resultado importante é a ausência de ênfase no comportamento "treinar, formar e desenvolver subordinados" no discurso dos gestores intermédios e no dos seus supervisores. $\mathrm{O}$ facto de emergir como um dos comportamentos menos presente no seu discurso poderá indiciar alguma desresponsabilização na identificação de necessidades de formação e definição de programas de desenvolvimento de subordinados. Contudo, o envolvimento dos gestores no desenvolvimento dos subordinados é essencial, por influenciar os comportamentos destes em direção aos clientes da organização e, assim, a qualidade do serviço prestado (Testa \& Ehrhart, 2005). Importante para a eficácia do gestor, a adoção destes comportamentos deverá ser promovida ${ }^{8}$, o que requer que os gestores intermédios não sejam assoberbados com tarefas técnicas e administrativas que lhes roubem tempo, ao contrário do que acontece atualmente, como se percebe no seu discurso «neste momento estou para assinar uma série de documentação que já lá está lá em baixo».

Conscientes dos constrangimentos a que se encontra sujeito o gestor na AP, parece-nos importante criar condições para que ele usufrua de maior liberdade para, por exemplo, definir com os subordinados os respetivos percursos de carreira e promover a sua mobilidade. Isto passa, nomeadamente, por dispor de tempo para adotar estes comportamentos, pela formação adequada dos próprios gestores (no que toca a gestão de $\mathrm{RH}$ ) e pelo reconhecimento do interesse da proximidade entre gestores e nível operacional da organização (MintzBerg, 2003), no que toca a definição de estratégias, conhecimento e implementação de práticas de $\mathrm{RH}$.

A importância da proximidade entre estes gestores e os subordinados é reforçada com a ênfase que se percebe no 
comportamento "cortesia e apoiar", comportamento que é dirigido a pares, subordinados e superiores do DS e que traduz a manifestação de consideração pela individualidade e necessidades dos elementos que trabalham consigo (especialmente os seus subordinados), «tem que ser, de certa forma, digamos que amigo», «ouvir os seus problemas»; o que sugere que a manifestação de consideração pelos subordinados é fundamental para a realização do trabalho, potenciando um bom funcionamento da equipa e agilizando o trabalho. A capacidade do gestor de dar suporte emocional a subordinados é especialmente importante quando estes desempenham atividade em contacto direto com o público, dada a carga afetiva deste trabalho (Testa \& EhrharT, 2005).

O discurso dos participantes permite perceber o DS enquanto um especialista que garante a legalidade e continuidade do sistema, uma interpretação que se apoia no facto do comportamento "proficiência profissional" ser dos mais valorizados e adotados, «deve naturalmente cumprir a lei», «E por regra são questões até... com algum grau de complexidade», «como sou o único jurista, cai cá tudo». Este gestor fornece aos clientes (internos e externos) informação que os órgãos de gestão de topo poderiam não proporcionar tão pronta ou profundamente, em função da natureza da informação solicitada; é, por isso, a ele que os órgãos de gestão mais recorrem para obter apoio.

De modo a ser-lhe possível exercer o papel de especialista, apoiando os diferentes níveis do sistema, é-lhe então necessário recolher informação, como se percebe pelo destaque dado ao comportamento "recolha e interpretação de dados" numéricos e outra informação para apoiar decisões superiores, que dizem respeito à própria organização, «a primeira coisa é saber se há alguma questão pendente», assim como ao seu meio «passar em revista os órgãos de comunicação social, a ver se há alguma coisa que nos interessa», criando condições para o gestor dar resposta à sua atividade diária. $\mathrm{O}$ apoio técnico requerido a este posto exige uma constante atualização da legislação e procedimentos que a organização deve obrigatoriamente adotar, o que requer que este gestor se mantenha atualizado, exigindo comportamentos contextuais de autodesenvolvimento. O reconhecimento desta posição de especialista organizacional poderá explicar a reduzida ênfase no comportamento "influenciar", sugerindo que não lhe é necessário despender esforços a persuadir supervisores e subordinados, dado que aquilo que ele diz é, à partida, aceito como correto.

De notar que o movimento de reforma na AP reforça a necessidade organizacional de um elemento especializado nas regras e procedimentos desse sistema. As exigências associadas a essas mudanças são, a nosso ver, refletidas na ênfase dada à adoção de comportamentos de Iniciativa Conscienciosa, no que toca à persistência diante de dificuldades, «entro muito cedo e saio muito tarde», «às vezes temos que os confrontar» e aprendizagem «fazer uma autoformação, tem que ler, tem que ler, muitas vezes não só relacionado com o trabalho, mas também para se atualizan».

O papel de símbolo do gestor (Mintzberg, 1973) é percebido no nosso estudo pelo realce dado aos comportamentos "representar a organização" e "comunicar". Curiosamente, Horne e Lupton, em 1965, observaram que gestores intermédios não dedicavam tipicamente muito tempo a comportamentos de representação, pelo que os nossos resultados parecem sugerir uma mudança no DI 
destes gestores (apesar de, sendo um estudo qualitativo, não procurarmos generalizações), refletindo o atual "estado de coisas" nas organizações e no seu ambiente, que Rousseau (1997) designa de "nova era organizacional". De notar que os nossos dados sugerem duas formas do comportamento "representar" do gestor, uma de desempenho de tarefa e uma contextual, considerando o efeito do comportamento a nível do sistema técnico nuclear da organização.

Especificamente no que se refere aos supervisores, o seu discurso sugere que esperam que os DS lidem autonomamente com as situações que surgem no dia-a-dia, encontrando soluções e evitando colocar problemas à sua consideração, «a capacidade de entender os problemas, poder resolvê-los sem grande complicação, encontrando os caminhos justos, mas encontrando os caminhos com facilidade», e que os DS planeiem e organizem o trabalho na sua unidade, definindo objetivos e coordenando o trabalho de modo a alcançar esses objetivos, monitorizando e controlando custos e os recursos económicos da organização, respeitando a legislação e procurando levar em consideração as características da organização na aplicação da lei.

Valorizam a dimensão de liderança deste gestor e de muitos dos seus comportamentos técnicos, especificamente "proficiência profissional", «conhecer muito bem internamente toda a complexidade do sistema, a legislação, as competências, os deveres, as necessidades do serviço, as orientações (...) do organismo em que se insere», o que reforça a natureza especialista deste gestor e a sua importância enquanto apoio técnico fundamental à gestão da organização.

\section{Conclusões}

Este estudo oferece suporte para a premissa segundo a qual a estrutura interna do desempenho individual do gestor é distinta da dos postos de não gestores, verificando-se que a natureza dos seus comportamentos se distingue conforme os comportamentos do gestor são dirigidos a pares e a supervisores ou aos subordinados. Consegue-se perceber a importância dos comportamentos deste gestor, que reforçam a natureza burocrática, que é característica das organizações da Administração Pública (e.g. comportamentos de administração e tarefas burocráticas e de proficiência profissional), assim como a importância dos comportamentos que permitem fazer face às exigências de um desempenho mais elevado e de esforços extra na AP (VAN WART, 2003), e que remetem para os comportamentos contextuais de persistência diante das dificuldades e de autodesenvolvimento, que nos permitem perceber o papel do gestor no processo de mudança de seu contexto organizacional.

Por outro lado, a ausência de adoção de comportamentos contextuais de iniciativa é coerente com o facto de estes contextos inibirem a adoção deste tipo de comportamento (PAINE \& Organ, 2000), apesar de verificarmos que eles são valorizados pelos gestores estudados, assim como pelos seus supervisores. Sabendo que os trabalhadores adotam os comportamentos que parecem ser valorizados pela organização e que não adotam (ou adotam menos) os comportamentos que percebem ser desvalorizados (Karambayya, 1990), é importante sensibilizar os atores organizacionais da AP para a adoção de comportamentos que no nosso estudo surgiram como menos enfatizados, demonstrando 
como esses comportamentos (e.g. delegar, iniciativa, cooperar) contribuem para a organização no seu todo e como os comportamentos contextuais e de tarefa (sempre associados) influenciam mais ou menos diretamente os colegas de trabalho (WERnER, 2000) e a organização a nível da eficácia na concretização de objetivos, sendo um importante recurso a mobilizar no momento atual da AP.

É necessário, principalmente, que se criem condições para que o gestor possa adotar esses comportamentos. Parece particularmente importante que se promova uma maior valorização e adoção de comportamentos de formação e desenvolvimento dos subordinados dos gestores intermédios, ocasionando dessa forma o desenvolvimento das competências dos vários elementos do sistema, ao mesmo tempo que, fazendo face às atuais necessidades de contenção na AP, torna-se possível confiar aos trabalhadores mais experientes o ensino de competências aos recém-chegados, evitando gastos adicionais com formação e socialização formal.

Em estudos futuros, é importante perceber em que medida os resultados obtidos neste trabalho podem ser generalizados aos gestores intermédios de toda a Administração Pública. Importa conhecer com pormenor quais os comportamentos adotados por estes, a sua frequência e natureza (de tarefa e contextual), assim como os seus preditores e as respectivas consequências no desempenho da organização.

Esse conhecimento permitirá avançar na compreensão dos processos que levam à adoção de diferentes comportamentos e à forma de promover os comportamentos dos gestores relacionados com melhores resultados organizacionais (BARTRAM, 2004), apoiando o gestor a gerir as dificul- dades associadas às mudanças na AP, nomeadamente ao apoiar processos de Recrutamento e Seleção (RS), e identificando áreas centrais de competências.

A nível do desempenho contextual importa não esquecer que a adoção extrema de alguns comportamentos pode revelarse prejudicial para a organização (BORMAN \& Motowidlo, 1993), como acontece com o comportamento "seguir regras e procedimentos organizacionais", que ao ser adotado de forma generalizada por todos os trabalhadores pode inibir a adoção de comportamentos de inovação (BORMAN \& Motowidlo, 1993). As organizações devem considerar as suas características ao promover diferentes comportamentos contextuais, tendo em atenção que alguns desses comportamentos, quando levados ao extremo, podem inibir o desenvolvimento organizacional.

No que toca a limitações, teria sido interessante solicitar aos supervisores que preenchessem diários de bordo do dia-a-dia de trabalho dos Diretores de Serviços (DS) e tê-los questionado acerca dos comportamentos adotados pelos DS. Contudo, dado que à altura das entrevistas aos supervisores não sabíamos que comportamentos caracterizavam o DI dos DS, entendeu-se não se questionar os supervisores acerca da adoção de comportamentos que ainda não tinham sido identificados.

As organizações de serviços, como as que compõem a AP, procuram promover a ação centrada no cliente, nas suas necessidades e características, colocando assim novas exigências aos trabalhadores. Os comportamentos contextuais promovem a criação de um ambiente de trabalho que facilita a introdução de mudanças, através da ajuda mútua entre trabalhadores, do autodesenvolvimento de competências, melhorando a imagem da organização e dos 
seus trabalhadores junto dos clientes. Comportamentos de cooperação, de cortesia, de ajuda e de motivação entre os elementos da organização e para com os clientes, adquirem assim uma importância fundamental (Burke \& CoOper, 2006).

Em um ponto em que a AP é sujeita a reestruturações de dimensão elevada, é importante analisarmos estes comporta- mentos com atenção, para a compreensão de quais são relevantes em cada posto de trabalho e a promoção da sua adoção, de forma a fornecer a estas organizações a energia necessária para lidar com as mudanças que enfrentam.

(Artigo recebido em janeiro de 2012. Versão final em maio de 2012).

\section{Notas}

Este artigo está escrito em português de Portugal.

1 Distinguindo-se esses comportamentos dos respectivos resultados.

2 Que "abrange o processamento, a transformação de energia ou de informação cujos ciclos de atividade compreendem as principais funções do sistema", tendo como função a transformação de energia dentro da organização (KATZ \& KAHN, 1978, p. 56).

3 Que se refere aos comportamentos de transformação principais desenvolvidos nesse posto de trabalho, que contribuem direta ou indiretamente para o sistema técnico nuclear da organização e serão potenciados pelos comportamentos contextuais.

4 Em algumas faculdades este posto é designado de "Secretário", sendo equivalente ao DS.

5 Exemplo: Quais os critérios que na sua opinião subjazem a uma avaliação positiva do desempenho de um DS? Quais os comportamentos que considera importante que um DS adote?

6 Descreva um dia de trabalho seu.

QSR N6 (NUD*IST 6) Versão 6.0; Copyright QSR International, Pty, Ldt.

8 Aliás, o atual sistema de avaliação de desempenho da APP (SIADAP) requer aos avaliadores que identifiquem áreas de formação para os seus avaliados (subordinados).

\section{Referências bibliográficas}

Arvonen, Jouko; Ekval, Göran. Effective leadership style: both universal and contingent? Creativity and Innovation Management, v. 8, n. 4, p. 242-250, 1999.

Bardin, Laurence. Análise de conteúdo. Edições 70: Persona, 1977.

Bartram, Dave. Assessment in organizations. Applied Psychology: an International Review, v. 53, n. 2, p. 237-259, 2004. 
Borman, Walter; Brush, Donald. More progress toward a taxonomy of managerial performance requirements. Human Performance, v. 6, n. 1, p. 1-21, 1993.

Borman, Walter; Motowidlo, Stephan. Expanding the criterion domain to include elements of contextual performance. In: SCHMitT, N.; Borman, W. C. e Associates (Eds.). Personnel selection in organizations, San Francisco: Jossey-Bass, 1993, p. 71-98.

Borman, Walter; MotowIDLO, Stephan. Task performance and contextual performance: the meaning for personnel selection research. Human Performance, v. 10, n. 2, p. 99-109, 1997.

Borman, Walter; Penner, Louis; Allen, Tammy; Motowidlo, Stephan. Personality predictors of citizenship performance. International Journal of Selection and Assessment, v. 9, n. 1/2, p. 52-69, 2001.

Burke, Ronald; CoOper, Cary L. The new world of work and organizations: implications for human resource management. Human Resource Management Review, v. 16, p. 83-85, 2006.

Campbell, Charlotte; Ford, Patrick; Rumsey, Michael; Pulakos, Elaine; Borman, Walter; Felker, Daniel; Vera, Maria; Riegelhaupt, Barry. Development of multiple job performance measures in a representative sample of jobs. Personnel Psychology, v. 43, p. 277-300, 1990.

Campbell, John; Mchenry, Jeffrey; Wise, Lauress. Modeling job performance in a population of jobs. Personnel Psychology, v. 43, p. 313-333, 1990.

Coleman, Venetta; Borman, Walter. Investigating the underlying structure of the citizenship performance domain. Human Resource Management Review, v. 10, n. 1, p. 25-44, 2000.

Conway, James. Additional construct validity evidence for the task/contextual performance distinction. Human Performance, v. 9, n. 4, p. 309-329, 1996.

Distinguish Contextual performance from task performance for managerial jobs. Journal of Applied Psychology, v. 84, n. 1, p. 3-13, 1999.

. Managerial performance development constructs and personality correlates. Human performance, v. 13, n. 1, p. 23-46, 2000.

DAFT, Richard; STEERS, Richard. Organizations: a micro/macro approach. Glenview: Scott, Foresman, 1986.

Duncan, R; Weiss, A. Organizational learning: Implications for organizational design. In: Staw, B. e Cummings, L. (Eds.). Research in organizational behavior. Greenwitch, CT: JAI Press, 1979, p. 75-123.

Fairholm, Matthew. Different perspectives on the pratice of leadership. Public Administration Review, v. 64, n. 5, p. 577-590, 2004.

Hattrup, Keith; O’Connell, Matthew; Wingate, Peter. Prediction of multidimensional criteria: Distinguish task and Contextual performance. Human Performance, v. 11, n. 4, p. 305-319, 1998.

Horne, J. H.; Lupton, Tom. The work activities of middle managers: An exploratory study. Journal of Management Studies, v. 1, p. 14-33, 1965.

Hosking, Dian-Marie; Morley, Ian. A social psychology of organizing. People, processes and contexts. London: Harvester Wheatsheaf, 1991.

KANTER, Rosabeth. The new managerial work. Harvard business review, p. 85-92, 1989. 
KaRAMBAYYA, Rekha. Contextualpredictors of organizational citizenship behavior. Paper presented at the National Academy of Management, San Francisco, 1990/08.

Katz, Daniel; Kahn, Robert. Psicologia Social das Organizações ( $3^{\mathrm{a}}$ ed.). São Paulo: Atlas, 1987.

Kelman, Steve. Public Administration and Organization Studies. In: Brief, A. e Walsh, J. P. (Eds.). Academy of Management Annals. New York: Erlbaum, 2007.

MintzBerg, Henry. Le management. Voyage au centre des organisations. Paris: Les éditions d'organisation, 1994.

MintzBerg, Henry. The nature of managerial work. New York: Harper \& Row, Publisher, Inc, 1973.

. Managers, not MBAs. San Francisco: Berrett-Koehler Publishers, Inc, 2003.

Morrison, Elizabeth. Organizational citizenship behavior as a critical link between HRM practices and service quality. Human Resource Management, v. 35, p. 493-512, 1996.

Muldrow, Tressie; Buckley, Timothy; Schay, Brigitte. Creating high-performance organizations in the public sector. Human Resource Management, v. 41, n. 3, p. 341-354, 2002.

Nutт, Paul C. Transforming public organizations with strategic leadership. Public Productivity through Quality and Strategic Management, p. 61-82, 1995.

PaINE, Julie; Organ, Dennis. The cultural matrix of organizational citizenship behavior: Some preliminary conceptual and empirical observations. Human Resource Management Review, v. 10, n. 1, p. 45-59, 2000.

Posner, Barry; SCHмidt, Warren. Determining managerial strategies in the public sector. Human Resource Management, v. 21, n. 2, p. 35-43, 1982.

Rousseau, Denise. Organizational Behavior in the New Organizational Era. Annual Review of Psychology, v. 48, p. 515-546, 1997.

Schraeder, Mike; Tears, Rachel; Jordan, Mark. Organizational culture in public sector organizations. Promoting change through training and learning by example. Leadership \& Organization Development Journal, v. 26, n. 6, p. 492-502, 2005.

Selznick, Philip. Foundations of the theory of organization. In: Shafritz, Jay e Oтt, J. Steven (Eds.). Classics of organization theory ( $3^{\text {rd }} \mathrm{ed}$.). California: Brooks/Cole Publishing Company, 1948, p. 114-123.

Sмith, Adam. Of the division of labour. In: Shafritz, Jay e Oтt, J. Steven (Eds.). Classics of organization theory ( $3^{\text {rd }}$ ed.). California: Brooks/Cole Publishing Company, 1976, p. 36-40.

Smith, C. Ann; Organ, Dennis; Near, Janet P. Organizational citizenship behavior: It's nature and antecedents. Journal of Applied Psychology, v. 68, n. 4, p. 653-663, 1983.

SPICER, Michael. The History of Ideas and Normative Research in Public Administration: Some Personal Reflections. Administrative Theory and Praxis, v. 30, n. 1, p. 50-70, 2008.

TAYLOR, Frederick. The principles of scientific management. In: SHAFRITZ, Jay e OTT, J. (Eds.). Classics of organization theory ( $3^{\text {rd }}$ ed.). California: Brooks/Cole Publishing Company, 1916, p. 69-80.

Testa, Mark; Ehrhart, Mark. Service leader interaction behaviors. Comparing employee and manager perspectives. Group \& Organization Management, v. 30, n. 5, p. 456-486, 2005. 
VALLE, Matthew. Crisis, culture and charisma: the new leader's work in public organizations. Public Personnel Management, v. 28, n. 2, p. 245-256, 1999.

Van Wart, Montgomery. Public-sector leadership theory: an assessment. Public Administration Review, v. 63, n. 2, p. 214-228, 2003.

Werner, Jon M. Implications of ocb and Contextual performance for human resource management. Human Resource Management Review, v. 10, n. 1, p. 3-24, 2000.

YIN, Robert K. Case study research: design and methods. Los Angeles: Sage. 2008.

YUKL, Gary. Managerial leadership: a review of theory and research. Journal of Management, v. 15, n. 2, p. 251-289, 1989. 


\section{Apêndice A: Protocolo de entrevista aplicado aos dirigentes intermédios (DS)}

\section{Guião de entrevista semiestruturado para dirigentes intermédios}

\section{Introdução}

Esta entrevista insere-se num trabalho de investigação que tem por objetivo compreender a "atividade dos dirigentes intermédios da Administração Pública", especificamente dos Diretores de Serviços. É isso que eu gostaria de explorar consigo, ou seja, gostaria que conversássemos acerca da sua atividade.

Os aspectos relativos à "confidencialidade, anonimato" e forma de tratamento dos dados já foram assegurados no pedido de colaboração, sendo a sua sinceridade fundamental para dar valor aos resultados. Permite que a entrevista seja gravada?

\section{Questões a colocar}

\section{Primeira secção}

1) Fale-me dos comportamentos que considera importante que um Diretor de Serviços adote. Relativamente à avaliação do trabalho desenvolvido por um Diretor de Serviços.

2) Quais os critérios que, na sua opinião, subjazem a uma avaliação positiva do desempenho de um Diretor de Serviços?

3) Quais os critérios que, na sua opinião, subjazem a uma avaliação negativa do desempenho de um Diretor de Serviços?

4) Um funcionário passa a Diretor de Serviços por nomeação, ficando em Comissão de Serviço. Fale-me dos critérios que apoiam esta nomeação e a sua eventual renovação.

\section{Segunda secção}

5) Descreva um dia de trabalho seu.

\section{Terminar a entrevista}

Existe mais algum aspecto acerca da atividade do Diretor de Serviços que gostaria de explorar?

No sentido de enriquecer o conhecimento da sua atividade, gostaria de lhe solicitar o preenchimento de um diário de bordo da sua atividade, registando as atividades que desenvolve no seu dia de trabalho.

Mais uma vez, agradeço a sua colaboração. 


\section{Apêndice B: Estrutura Interna do desempenho individual dos gestores intermédios da Administração Pública}

\section{A. Desempenho de tarefa}

\section{1) Comportamentos de interação e comunicação}

Comunicar e manter os outros informados: comunicar com eficácia oralmente e por escrito; informar subordinados, supervisores e outros; obter e de seguida transmitir informação para aqueles que devem tomar conhecimento dela.

Representar a organização no exterior em situações formais; manter uma boa imagem organizacional junto de clientes, público, acionistas, governo; lidar com problemas de utentes/clientes.

Influenciar/convencer: persuadir outros na organização e aceitar as suas boas ideias, apresentar clara e decididamente as suas posições e argumentar eficazmente acerca delas.

\section{2) Comportamentos de liderança e supervisão}

Orientar, avaliar, motivar subordinados e dar feedback: dar orientação e direção, motivar; apresentar feedback apropriado; ajudar a definir objetivos e manter padrões de desempenho; monitorizar e avaliar a qualidade do desempenho dos subordinados.

Treinar, formar e desenvolver subordinados: identificar necessidades de formação e desenvolver programas e materiais adequados ou assegurar que estes sejam desenvolvidos; formar e treinar subordinados; auxiliá-los no melhoramento de competências de trabalho.

Coordenar subordinados e recursos: utilizar adequadamente pessoal e outros recursos para aumentar a eficácia; coordenar o trabalho e equilibrar os interesses da unidade com os da organização; negociar de modo a alcançar a melhor utilização dos recursos organizacionais. Desenvolver práticas de gestão de RH para a unidade, encorajar e promover a cooperação entre subordinados.

\section{3) Comportamentos técnicos e de gestão}

Planejar e organizar: formular metas e objetivos a curto e longo prazo; antever possíveis problemas e tendências e desenvolver estratégias para lidar com essas situações; organizar e atribuir prioridades ao trabalho; planejar e organizar o seu trabalho; gerir o tempo. 
Proficiência profissional (perícia): aplicar no trabalho conhecimentos de domínio técnico (em oposição a de gestão) e prestar informação técnica.

Administração e tarefas burocráticas: desempenhar tarefas administrativas diárias (rever relatórios, analisar correio, aprovar pedidos de rotina); manter registos corretos e documentar acontecimentos, administrar políticas e procedimentos adequados.

Resolver problemas: tomar decisões corretas atempadamente, baseando-se na informação disponível; prestar atenção e levar em consideração as informações relevantes ao tomar decisões e desenvolver soluções eficazes para lidar com problemas organizacionais.

Provimento de pessoal: manter pessoal e mão-de-obra; recrutar, entrevistar, selecionar, contratar, transferir e promover pessoas na organização; e manter um sistema eficaz de desenvolvimento de carreira. Decidir os critérios para as diferentes posições; construir e manter uma equipa de gestão coesa e identificar e desenvolver substituições de pessoal.

Controlar recursos: controlar custos e recursos de pessoal; distribuir fundos internamente e monitorar e supervisionar a sua utilização dentro de constrangimentos e orientações existentes. Enfatizar o cumprimento de prazos e garantir que padrões definidos sejam atingidos e os custos controlados.

Delegar: atribuir deveres e responsabilidades de acordo com os respectivos interesses e capacidades, bem como as necessidades da organização; delegar realmente autoridade e responsabilidade para promover o crescimento dos subordinados; evitar invadir a responsabilidade delegada.

Recolher e interpretar dados: saber quais os dados relevantes para resolver um determinado assunto; interpretar corretamente dados numéricos e outra informação, promovendo inferências corretas; apresentar recomendações para ações futuras; organizar ou coordenar a organização correta de dados de natureza interna e externa, que permitam resolver problemas e tomar decisões.

\section{B. Desempenho Contextual}

\section{4) Suporte Pessoal}

Cooperar: aceitar sugestões de colegas, superiores e subordinados, seguir as direções/ sugestões de colegas e subordinados e colocar os objetivos da equipa acima dos objetivos pessoais; informar outros de acontecimentos ou exigências que poderão afetá-los.

Cortesia e apoiar: revelar consideração, cortesia e tato no relacionamento; manifestar preocupação pessoal por subordinados, colegas e superiores; apoiar/proteger subordinados da forma mais adequada; dar suporte emocional para problemas pessoais a subordinados, colegas e superiores.

\section{5) Suporte Organizacional}

Representar favoravelmente a organização junto de elementos exteriores quando não está em representação formal da organização; defendê-la quando outros a criticam; promover os seus resultados e atributos positivos e expressar satisfação pessoal com a organização.

Lealdade: permanecer com a organização apesar de privações ou incómodos temporários, tolerar dificuldades e adversidades temporárias pacientemente e sem queixas, e subscrever publicamente a missão e os objetivos organizacionais. 
Concordar: concordar com as regras e os procedimentos organizacionais; adotar procedimentos organizacionais; encorajar outros a concordar com as regras e procedimentos organizacionais e sugerir melhorias de procedimento, administrativas ou organizacionais.

\section{6) Iniciativa Conscienciosa}

Persistir: revelar esforço extra para completar as suas tarefas com sucesso, apesar de condições difíceis e dificuldades; atingir objetivos mais difíceis e desafiantes do que normalmente; completar trabalho dentro do prazo, apesar de prazos-limite excecionalmente pequenos; e desempenhar o seu trabalho num nível de excelência que ultrapassa significativamente as expectativas normais.

Iniciativa: tomar a iniciativa de fazer tudo o que é necessário para completar um objetivo da equipa ou organizacional, mesmo que implique aspectos que normalmente não fazem parte dos seus deveres; corrigir situações irregulares que identifica e encontrar trabalho adicional para realizar.

Autodesenvolver-se: desenvolver competências no seu próprio tempo livre; voluntariarse para oportunidades de desenvolvimento na organização e procurar adquirir novos conhecimentos e competências através de outros na organização ou novas tarefas.

Nota: os comportamentos ausentes do discurso dos participantes não se inserem nesta proposta de estrutura de DI dos gestores intermédios da AP. 


\section{Resumo - Resumen - Abstract}

O desempenho individual de gestores intermédios da administração pública portuguesa Catarina Brandão e Filomena Jordão

Este estudo de caso foca o desempenho individual (DI) de gestores intermédios da Administração Pública Portuguesa, procurando clarificar a estrutura interna do seu DI, considerando as dimensões de desempenho de tarefa e contextual, propostas por Borman e Motowidlo (1993, 1997). Neste sentido, recolheu-se informação junto a dirigentes intermédios e seus supervisores em uma organização do setor de Educação, recorrendo a entrevistas semiestruturadas e diários de bordo, e submeteu-se a informação recolhida à análise de conteúdo. O discurso dos participantes permite perceber que reconhecem a natureza multidimensional do DI dos gestores intermédios, possuindo uma concepção mais diferenciada em nível de desempenho de tarefa. Sugere ainda a pertinência de promover nestes gestores a valorização e adoção de comportamentos de formação e desenvolvimento de subordinados, de delegação, de planeamento e organização, bem como de provimento de pessoal, na medida em que estes comportamentos, quando adotados por gestores de linha, traduzem uma prática de trabalho de desempenho elevado.

Palavras-chave: Desempenho individual; Desempenho de tarefa e contextual; Gestores intermédios da Administração Pública.

\section{Desempeño en el trabajo de gestores públicos intermedios en Portugal Catarina Brandão y Filomena Jordão}

Este estudio se centra en el desempeño laboral de gestores de nivel intermedio en el sector público portugués, principal contexto organizacional de Portugal. Nuestro objetivo es esclarecer la estructura interna en que se evalúa el desempeño de los gestores intermedios; para ello, se examina la dimensión desempeño de tarea y desempeño contextual, propuesta por Borman y Motowidlo $(1993,1997)$. Por eso, llevamos a cabo entrevistas semiestructuradas a los trabajadores, a la vez que recogimos diarios de trabajo, y sometimos los datos a un análisis de contenido. Los análisis revelan que los participantes reconocen el carácter multidimensional del desempeño laboral de los gestores intermedios; sin embargo, tienen una percepción diferenciada en cuanto al desempeño de tarea. Los resultados también sugieren la importancia de fomentar el reconocimiento, de la adopción de estrategias de formación y desarrollo hacia los subordinados, además de estrategias de delegación, planificación, organización y emplantillamiento de personal, ya que estas prácticas de gestión de personal se consideran de alto rendimiento en el trabajo.

Palabras clave: Desempeño laboral; Desempeño de tarea y contextual; Gestores del sector público.

\section{The job performance of middle level managers in the Portuguese public sector Catarina Brandão and Filomena Jordão}

This case study focuses on the middle manager's Job performance (JP) in the Portuguese public sector, Portugal's major organizational context. Our objective is to clarify these middle managers' JP's internal structure, considering the task and contextual performance dimensions proposed by Borman e Motowidlo (1993, 1997). To do so, we conducted semi-structured interviews and gathered work diaries focusing on the middle manager's Job performance, submitting the data to content analysis. The analyses reveal that the participants' discourses acknowledge these middle managers' JP's multidimensionality. They show as well a more differentiated perception of their task performance. Results also suggest the importance of 
fomenting in these managers the appreciation and adoption of training and development behaviors towards subordinates; delegating; planning and organizing; and staffing, since these personnel management practices, when adopted by middle managers, translates as a high performance work practice.

Keywords: Individual performance; Task and contextual performance; Public sector middle level managers.

Catarina Brandão

PhD em Psicologia, vinculada à Faculdade de Psicologia e de Ciências da Educação da Universidade do Porto (FPCEUP/ PT). Contato: catarina@fpce.up.pt

Filomena Jordão

PhD em Psicologia, vinculada à Faculdade de Psicologia e de Ciências da Educação da Universidade do Porto (FPCEUP/ PT). Contato: fjordao@fpce.up.pt 